\title{
Educating Tomorrow's Cardiac and Thoracic Surgeons in Canada: An Evolving Process
}

\author{
David S. Mulder*, M.D.,F.R.C.S.().
}

* To whom correspondence should be addressed: Department of Surgery, Montreal General Hospital, McGill University, 1650 Cedar Ave., Montreal, QC, Canada H3G 1A4

\section{INTRODUCTION}

Societal (1), technological, organizational (2), and educational developments during the past ten years have brought about increasing pressures for change in the graduate medical education of cardiac and thoracic surgeons (3). These changes effectively lengthened their training to eight years and created a double standard for the education of a thoracic surgeon. A task force mandated by the Royal College of Physicians and Surgeons of Canada nucleus committees in both cardiac and thoracic surgery, with the support of the Canadian Society of Cardiovascular and Thoracic Surgeons, addressed these issues and made the following recommendations: cardiac surgery and thoracic surgery should each become a primary specialty with its own nucleus committee. Each specialty would require six years of training, with the possibility of obtaining certification in both specialties after an additional eighteen months of training. Each specialty could also be entered after the completion of full training in general surgery. In addition, the task force urged the development of a curriculum to guide educational objectives in each specialty. These changes promise to create a flexible, shorter, and more focused program for cardiac and thoracic surgeons in both university and community settings.

\section{HISTORY OF CVT SURGERY IN CANADA}

Thoracic surgery in Canada evolved from the innovative efforts of a pioneering group of general surgeons led by Gallie and Archibald, who developed their skills through the experience of treating war-time chest wounds (4). Subsequently, septic diseases of the lung and pleura secondary to pulmonary tuberculosis provided the opportunity to introduce these early thoracic surgical skills to civilian practice. With the advent of positivepressure ventilation and anesthesia, elective thoracotomy became feasible. Bronchogenic carcinoma and formal resection for pulmonary tuberculosis then expanded the indications for this procedure. Thus, to accommodate the growing need for thoracic surgeons, formal training programs emerged. In 1946, the Royal College of Physicians and Surgeons of Canada set the first certification standards for surgery.

Thoracic surgeons laid the foundation for the exciting growth and development of cardiac surgery in Canada. In 1962, the Royal College of Physicians and Surgeons established a combined qualification in cardiovascular and thoracic surgery for which full training and certification in general surgery were prerequisites. Through F.G. Pearson, a certificate of competence in thoracic surgery originated in Toronto and was approved by the Royal College in 1976. The Pearson group emphasized the need for appropriate training 
in the evolving specialty of general thoracic surgery.

\section{PRESSURES FOR CHANGE}

In the past decade, graduate medical education for cardiac and thoracic surgeons in Canada has undergone numerous changes, which encompass the following:

* Clinical clerkship or the final year of medical school has effectively replaced internship in most Canadian medical schools.

* Two pathways to provincial licensure were introduced by Quebec in 1989 and 1990: a twoyear residency in family medicine, or successful completion of specialty training. Virtually all provinces have now introduced similar criteria for licensure, based on national guidelines.

* A core training in surgery was introduced by the Royal College in 1992.

* The duration of general surgery training prior to certification has been extended to five years.

* Training requirements for certification in thoracic surgery were modified to include a minimum of twelve months of senior experience in thoracic surgery and six months of senior training in cardiac surgery.

* Vascular surgery has become recognized as a training program for certification of special competence. A route will still exist for cardiothoracic surgeons to become eligible for vascular surgery qualification.

* There has been an overall decrease in funded residency positions in all training programs in Canada.

* All provincial governments are attempting to relate funded positions for residency training to predicted manpower needs in each specialty. Subspecialties such as cardiac and thoracic surgery will be encouraged to look at inter-university cooperation or regionally-based training programs.

* Reciprocity for training in Canadian cardiothoracic surgery programs no longer exists in U.S. certification processes.

These developments have in a minimum training of eight years to acquire eligibility for certification in cardiothoracic surgery. Considering the fact that many residents pursue a fellowship in pediatric cardiac surgery, thoracic transplantation, or thoracic oncology, many recent graduates were have been required to spend ten years in training before they could practice as consultant specialists. This was a major deterrent for medical students considering a career in cardiothoracic surgery in Canada. The increased duration of training required for general thoracic surgery created a double standard and, thus, confusion among residents, program directors, and examiners. Furthermore, the new core training program have little input from cardiothoracic surgeons due to the fact that full training in general surgery remained a self-contained, fiveyear prerequisite for entering cardiothoracic training programs.

\section{ROYAL COLLEGE TASK FORCE}

These general and specialty-specific changes precipitated a review of current training requirements for cardiac and thoracic surgeons in Canada. A task force was mandated by the Royal College nucleus committees in both cardiac and thoracic surgery with the full support of the Canadian Society of Cardiovascular and Thoracic Surgeons. 
Simultaneously, North American leaders in thoracic surgery sponsored a Joint Conference on Graduate Education in Thoracic Surgery (5). There had been many demands for review of residency education in thoracic and cardiac surgery in our specialty journals (6), none of which were as poignant and influential as Richard Peters' editorial in the Annals of Thoracic Surgery (7). Peters questioned the appropriateness of a five-year program in general surgery prior to spending two years of suboptimal training in both cardiac and thoracic surgery, and questioned the duration and educational sequence of the current training program in thoracic surgery. He called for a complete revision of the education of cardiac and thoracic surgeons in terms of length, content, and utilization of modern educational technology.

The Royal College task force met both in conjunction with North American thoracic surgical meetings and separately at the Royal College headquarters in Ottawa. A Royal College panel considered the "ideal" training of the cardiothoracic surgeon during its annual meeting in Vancouver in September 1993. Just prior to one of its final meetings, this task force had the privilege of hearing Aldo Castaneda's presidential address (8) during the American Association of Thoracic Surgeons meeting. Castaneda's plea for a shorter, more appropriate education for cardiac and thoracic surgeons had a profound influence on the final deliberations of the task force.

Recommendations were developed and referred to the Canadian Association of Surgical Chairmen, the Royal College Committee on Specialties, the Training and Evaluation Committee, the Credentials Committee, and the Accreditation Committee, where they were modified further. The finalized version was approved by the Royal College Council in September 1994. The major recommendation was to establish cardiac surgery and thoracic surgery as separate primary specialties, each with its own nucleus committee.

Each specialty produced a revised "Objectives of Training and Specialty Requirements" specific to resident needs (Tables 1 and 2). Implementation of these requirements will be under the direction of a given university's associate dean of postgraduate education and its department of surgery after site accreditation by the Royal College. The first training prerequisite will entail an approved core training in surgery. Approved programs in general surgery, vascular surgery, cardiac surgery, and thoracic surgery will be required to offer training opportunities for residents in the new primary specialties. This new training pathway should be offered as early as July 1996 with some type of "grandfather" status for existing cardiothoracic and thoracic surgery programs.

The newly defined pathway will enable residents to become masters of their selected clinical specialty at a relatively young age. Furthermore, the year of academic enrichment included within the six-year program allows access to the recently approved Clinician Investigator program of the Royal College of Physicians and Surgeons. This program will bring residents to the equivalent of a doctoral level of scholarship by adding two or three additional years of study at the branch point of their year of academic enrichment, thus providing a logical model for the education of the future teachers and academic leaders in thoracic and cardiac surgery as emphasized by Pories and Aslakson (9).

These recommendations, creating separate primary programs in cardiac and thoracic surgery, were reached after extensive consultation with all concerned stakeholders. There was outstanding cooperation with the general surgical specialty committee under the direction of E. Monaghan. As a result, a medical student may now enter a shortened, more focused training program for either cardiac or thoracic surgery. Training requirements and examinations will be appropriate for each specialty. In addition, it is possible for those certified in general surgery to enter either cardiac or thoracic surgery, maintaining flexibility for the candidate wishing to pursue community practice. The new pathways provide the equivalent of four years of training in "surgery in general" under the direction of a cardiac or thoracic program director. This plan should afford professional and personal maturation while eliminating the competition for indexed general surgical operations that are currently shared by consultant specialists in general surgery, and senior residents proceeding to cardiac or thoracic training. 
Under the new program, specialists will have a rich experience during a six-year residency in cardiac or thoracic surgery, which includes graded responsibility. Their prerequisite education begins with two years of core training in surgery. This 24-month core period can be individualized to meet the particular educational needs of the future specialist by enabling the selection of electives in appropriate surgical or medical rotations. This core training period is coordinated by a core faculty committee comprised of surgeons representing each of the participating surgical specialties, and is chaired by one of these specialists. The overall direction of the resident, including the selection of electives during the six months allotted for this purpose, is the responsibility of the program director of the chosen surgical specialty (i.e., cardiac or general thoracic surgery).

During the third and fourth years, residents in both streams spend six months as junior residents in general thoracic surgery and six months as junior residents in cardiac surgery. Thoracic stream residents pursue a 12 month senior rotation in general surgery, which might include emphasis on cervical or oncologic surgery. Cardiac stream residents perform six months of senior general surgery residency and six months of pediatric cardiac surgery. The year of academic enrichment may be taken at any suitable point in the educational sequence as determined by the program director and the resident, but is listed as the fifth year in Tables 1 and 2 for clarity. All six years of training are supervised by the program director in general thoracic or cardiac surgery, in collaboration with the core program director and the general surgery program director. This arrangement will allow effective implementation of a defined and coordinated curriculum for all years of training.

Surgical residents who have completed training in general surgery can enter either cardiac or thoracic training programs. Each candidate's credentials will be reviewed and should be creditable for up to four years of acceptable training in the new pathway to certification in cardiac or thoracic surgery. Certification in both thoracic and cardiac surgery will require an additional eighteen months of training. With Royal College approval obtained by program directors, some cross-training may be accommodated during elective rotations or during the academic enrichment year. Thus, certification in both cardiac and thoracic surgery can theoretically be achieved within seven years.

The task force recognized the complexity of the transition period with respect to accreditation, credentialing, and examination. All program directors will be encouraged to develop the new programs on the basis of a curriculum in both thoracic and cardiac surgery. This will allow effective evaluation of the changes once implemented.

\section{THE FUTURE}

The task force realizes that merely changing the duration and content of training will not be enough in itself. There must be a renewed dedication to the education of thoracic and cardiac residents by all program directors and staff surgeons in each of the relevant disciplines. Programs must be structured on a welldesigned curriculum (10) and regular three-way evaluations must be an integral component of all programs. A renewed level of cooperation must be achieved between all surgical disciplines under the umbrella of a division of surgical education in university departments of surgery.

The Canadian Association of Cardiovascular and Thoracic Surgeons has a new opportunity to revitalize its organizational structure to reflect the reality of its two new component specialties (11). The Specialty Society can now take a leadership role in the arena of education and health care delivery, supporting the development of a curriculum and a plan of education based on work-force needs for the cardiac and thoracic surgeons of tomorrow. The Society should study future needs and participate proactively in determining the number of funded positions available for cardiac and thoracic surgery residents.

With this commitment, the specialties of cardiac and thoracic surgery in Canada can approach the horizon of 
the 21 st century with confidence and pride in a revitalized and flexible education process focused on the needs of our students and our society.

\section{REFERENCES}

1. Maudsley, RF. Post-graduate medical education: responding to changing health and social needs. Annals of the Royal College of Physicians \& Surgeons of Canada 25(7): 429-432; 1992.

2. Ruedy, J. History of specialty residency funding in Canada. Canadian Medical Association Journal 148(9): $1554-1558 ; 1993$.

3. Anderson, RP. Change and thoracic surgery. Journal of Thoracic \& Cardiovascular Surgery 103(2): 186$193 ; 1992$.

4. Delarue, NC. Thoracic Surgery in Canada. A Story of People, Places, and Events. The Evolution of a Surgical Specialty. Toronto: B.C. Decker Inc; 1989.

5. Report on the Joint Conference on Graduate Education in Thoracic Surgery. Annals of Thoracic Surgery 55(5): 1349-1356; 1993.

6. Orringer MB, Cooper JD, Magovern G, et al. The continuing dilemma of general thoracic surgery. Where to now? Journal of Thoracic \& Cardiovascular Surgery 97(5): 649-653; 1989.

7. Peters, RM. Should we care? Do we care? What should we do? Annals of Thoracic Surgery 51(5): 807$808 ; 1991$.

8. Castaneda AR. The making of a cardiothoracic surgeon: an Appollonian quest. Journal of Thoracic \& Cardiovascular Surgery 108(5): 806-812; 1994.

9. Pories W, Aslakson HM. The surgical residency. The job description does not fit the job. Archives of Surgery 125: 147-149; 1990.

10. Luce, EA. A graduate surgical education curriculum. ACS Bulletin: 27-30; 1994.

11. Roth JA, Balch CM. Thoracic surgery training: it is time for a change. Annals of Thoracic Surgery 51(5): 818-819; 1991.

\section{BIOGRAPHY}

David S. Mulder, M.D., F.R.C.S.(C), is currently Surgeon-in-Chief at the Montreal General Hospital and Chaiman of the Department of Surgery at McGill University (Montreal, Quebec, Canada). Dr. Mulder's residency in general surgery was completed at McGill. His education in cardiothoracic surgery was at the University of Iowa under Dr. J. L. Ehrenhaft.

Dr. Mulder is currently on the Council of the Royal College of Physicians and Surgeons and has had a long interest in graduate surgical education.

Copyright (C) 1996 by MJM 